suitability, considering that they have stood the test of so prolonged a trial. Yet there are some who do not hesitate to call these articles of food, which are so extensively consumed, poisons, mainly, as far as I can gather, because these foods do not happen to agree with themselves. It is true that there are a few persons (whom, without any intention of being offensive, I should describe as physiological degenerates) who find that such articles of food do not agree with them, but it is illogical to argue from such a premiss that therefore they are unsuited to the great majority whose digestive functions are more happily regulated.

The diet of gouty patients undergoing spa treatment should be simple-that is, the meals should not be made up of too many articles. Simplicity of food means facility of digestion. Certainly meat, even red meat, should not be excluded from the diet. No class of foodstuff is so productive in energy as animal food, and as most cases of chronic gout are suffering from lowered vitality and want of tone animal food in at all events moderate quantity is distinctly indicated. My experience supports the truth of this view, as I advise in the great majority of cases of chronic gout the taking of at least one meat meal a day. The exclusion of any article of diet or of any class of food without taking into account the surroundings of the case and the peculiarities of the individual is unscientific. Those articles of diet that are known in the individual to favour intestinal fermentation and putrefaction should certainly be avoided, and it may be taken, I think, as a general rule that a sense of discomfort after a meal indicates that some article or articles of food have been taken which are not beneficial to the individual in his present condition. I attach great importance in such cases to the reduction of the starchy articles of food, but not to the total exclusion of what I believe to be the comparatively harmless potato. It is remarkable how frequently one hears from gouty patients the emphatic statement, "I never eat potatoes." I must confess that I do not know of any good and sufficient reason for this wholesale condemnation of such a common article of diet. Undoubtedly amongst those gouty patients who suffer from an inability to digest starchy articles of diet perfectly - in other words, who suffer from amylaceous dyspepsia-a reduction for the time in the amount of starchy foods taken, including potatoes, is desirable; but the recognition of the existence of amylaceous dyspepsia is a fairly easy matter and when present it can be suitably treated. Certainly those persons who are gouty and who are also fat should be very sparing in the use of potatoes as of other carbohydrate, forms of food. I wish, however, to protest against the too general exclusion of so common and useful an article of diet as the potato from the food of the gouty. Equally wrong, in $\mathrm{my}$ opinion, is the total exclusion of sugar from the dietary of all gouty individuals. Undoubtedly, in certain individuals sugar may do harm, as in the cases of gouty persons who are fat, or who suffer from glycosuria, or who are prone to attacks of eczema, and in such it should be cut off; but that is no reason for the exclusion of it from the dietary of all gouty patients, especially those who are at the same time gouty and thin. I know of many gouty individuals who take sugar with absolute impunity. Some gouty subjects undoubtedly digest starchy articles of diet very badly, and in such fats may well take the place of starches. Fat bacon, properly cooked, is generally well digested by gouty individuals.

A fair proportion of vegetable food should be taken with two meals each day. The choice of vegetables will depend upon the digestive capacity of the patient, but, excepting the potato, as a rule those vegetables that grow above ground are preferable to root vegetables.

Stated as a general principle a person who is subject to gout is better without alcohol in any form. There are, however, some who require a little alcohol, either to aid digestion or to enable them to get through their work, and here $\mathrm{I}$ am entirely in accord with the advice give by Dr. J. F. Goodhart, that if a man requires any stimulant at all it is a matter which he must decide by experiment for himself, for no medical man can tell him. If alcohol is necessary or desirable the form in which it is to be taken is frequently a matter which the patient can decide better than the medical man; but I would insist upon the importance of definitely limiting the amount to be taken and of restricting its consumption absolutely to meals. Some patients find that a little whisky or brandy suits them best, others find a light still moselle preferable, while a few-but in my opinion only a very limited number-find that a light claret agrees best with them. Champagne is a wine which is seldom suited to the gouty, especially if taken daily.

As previously stated, as little complexity as is possible in the meals is the main desideratum in the dietary of the gouty, and in a few intractable cases of chronic gout it may even become necessary to reduce the dietary for a time to the simplest possible condition-namely, to two articles -lean meat and water. There are a few cases of chronic gout which undoubtedly improve and even recover on an exclusive diet of red meat and hot water. These are generally cases of chronic gouty arthritis which have failed to yield to the ordinary methods of treatment and which are accompanied by obstinate derangement of the gastro-intestinal tract, as evidenced by dyspepsia, flatulence, acid eructations, pyrosis, and offensive stools. I have successfully treated a few such carefully selected cases of chronic gout by the employment of this, the so-called "Salisbury" treatment and beneficial results have also been obtained by Mr. Armstrong. It is essential before placing a patient on such diet that the urine should be carefully examined, as any advanced condition of kidney disease contra-indicates the employment of such a dietary. If the evidence of kidney derangement is only slight the adoption of the dietary is not contra-indicated, but the urine must be carefully examined every two or three days, as any considerable increase in the albuminuria would at once be an indication for the discontinuance of this special diet. Gouty patients suffering from organic heart disease with any failure of compensation should never be placed on this dietary.

The dietary in cases of rheumatoid arthritis should be as liberal as the digestive organs allow. Any food that the patient knows from his experience agrees with him may be allowed. It is essentially a disease that requires good and nutritious feeding and I have seen many cases of rheumatoid arthritis which have gone thoroughly to the bad through the initial error of mistaking the disease for gout and treating it with a spare diet.

Queen Anne-street, W.

\section{CONGENITAL DISPLACEMENT OF THE HIP. 1}

BY NOBLE SMITH, F.R.C.S. EDIN.

SENIOR SURGEON TO THE CITY ORTHOP.EDIC HOSPITAL, LONDON.

IN reviewing the general treatment of this affection I would offer the following conclusions:-1. That in all cases and at all ages some good may be effected by treatment. 2. If the displaced head of the femur has formed a firm bearing against the pelvis so that no tendency to increase of deformity exists, and the difficulties of walking are slight, then we may devote our energies to counteract lordosis by mechanical support, freeing adverse contractions such as those of the adductors and equalising the length of the legs when only one side is involved. Sometimes when both sides are affected there may be inequality in length of legs. 3. If the head of the femur is freely moveable up and down (telescopic) then some measures must be adopted to prevent increase of deformity, and the least that can be done is to recommend recumbency or the use of some apparatus to keep the weight off the affected limb. If such measures are taken we may as well also attempt to improve the position of the head of the femur or entirely reduce the dislocation. Until the age of seven years all congenital dislocations can be reduced. This is Lorenz's dictum and his view seems correct. In single displacements the time limit may be extended to nine years of age. These limits are not absolute, for much older patients may occasionally have their hips replaced.

As to the permanent result of reduction, the exact degree of success depends npon the condition of the joints. If the head of the femur is very deficient in form and the acetabulum very shallow or misshapen the result can hardly be as satisfactory as when the bones and other joint structures are less abnormal. In any case, however, if we keep the bones in place sufficiently long (about two years) we may expect a more or less satisfactory result. This fact is already

1 A paper delivered before the Fourteenth International Congress of Medicine at Madrid, April 25th, 1903. 
proved by the effect of treatment of cases previously published, cases in which several years have elapsed after treatment has been completed without any relapse having occurred. In some of such cases previously noted it is highly probable that complete reduction had not been accomplished, the retention of the head of the femur having been the result of the formation of a false joint; the occurrence of such false joints is well known to surgeons as happening after traumatic unreduced dislocations. The reduction by means of opening the joint with or without efforts to cut a new joint or otherwise interfere with the joint structures with the knife is at the present time not satisfactory, whereas the operation by manual reduction assisted by division of contracted muscles as perfected by Lorenz has been highly successful and is therefore recommended by me.

Treatment by manipulative reduction. - In England, since Dr. Lorenz visited us, questions have frequently arisen as to the treatment of congenital displacement of the hips by his particular method. To do full justice to the subject would necessitate the writing of a treatise or at least a long paper. I have therefore selected the more practical questions which have been put to me and have answered them as concisely as possible. I hope that this may prove useful to those practitioners who are interested in the subject.

\section{Practical Questions.}

1. Question: What is the condition of the joints in congenital displacement of the hips?-Answer: The condition varies very much; the bones may be very defective in shape, the head of the femur very small and misshapen, and the acetabulum very shallow. On the other hand, the appearance shown by x-ray photography may be perfect or apparently so. The upper and posterior borders of the socket are very frequently deficient. The capsule is enlarged and there is often a condition of hour-glass contraction and the upper ridge of the cotyloid cartilage may be bent down into the acetabulum. The ligamentum teres may be attenuated or absent. It is not my purpose to discuss these points at greater length upon this occasion because our evidence upon the subject is yet far from complete. Moreover, it is quite possible that whatever the exact condition of the joint reduction of the displacement will have a good effect. Even if the head of the femur fails to pass through the contracted neck of the capsule, or is in other ways prevented from assuming absolute contact with the acetabulum, yet the pressure of the head of the bone directly inwards will in all probability lead to absorption of such intervening tissues and to the formation of an adventitious cavity.

2. Question: Can the head of the thigh bone be brought into the acetabulum or into contact with the flat surface that represents that socket in some cases without an operation which involves opening the joint?-Answer: When both hips are affected this can, without doubt, be done up to the age of seven years. When only one hip is affected the reduction can be accomplished with practical certainty up to the age of nine years. Reduction may, however, be effected in much older children and even in adults (Lorenz). It is generally necessary to prepare these older patients by preliminary exercises. In my own cases I have succeeded with one patient aged $11 \frac{1}{2}$ and another aged 12 years without preparation and in one case aged 18 years after a year's previous treatment.

3. Question: What evidence have we that the head of the femur is really placed in its proper position at the time of the operation?-Answer: (1) The head of the femur is felt and often heard to slip over an edge and settle in a new position; (2) the hollow in the groin which has previously existed is filled up and in unilateral cases becomes equal to the sound side; (3) the thigh is distinctly lengthened, measured from the centre of the body to the knee; and (4) so long as the joint is "out" the leg may be extended in a straight line with the thigh (Fig. 1, dotted line), the limb being at right angles with the patient's body (Fig. 2), but directly the head of the femur is in place the full extension cannot be made, as by the lengthening of the limb the hamstrings become too tight to allow of full extension. In operating these symptoms may be made more apparent by displacing the joint and again reducing it several times.

4. Question: After reduction what position is necessary to maintain the joint surfaces together"--Answer: The limb must be kept at right angles to the body (Fig. 2) and the knee pressed backwards until it is posterior to the centre of the body (Fig. 1). The knees will be seen below the level of the line A B. This position brings the head of the femur forward into its capsule. In the majority of cases the socket is deficient above and posteriorly, so that if the limb is not

FIG. 1.

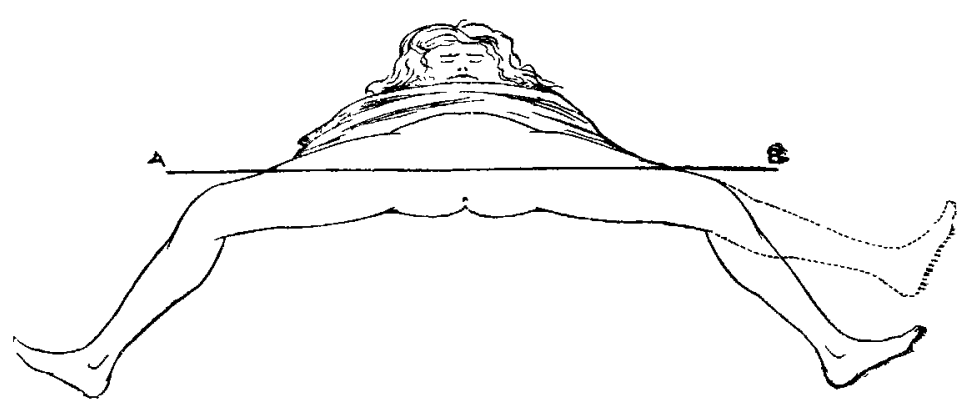

Extremely abducted position of limbs after operation, the knees being below the transverse median line $\mathrm{A} B$.

kept at right angles to the body (Fig. 2) the head of the femur will tend to slip upwards, and if the limb is not abducted backwards (as shown in Fig. 1) the femoral head will tend to slip backwards.

FIG. 2.

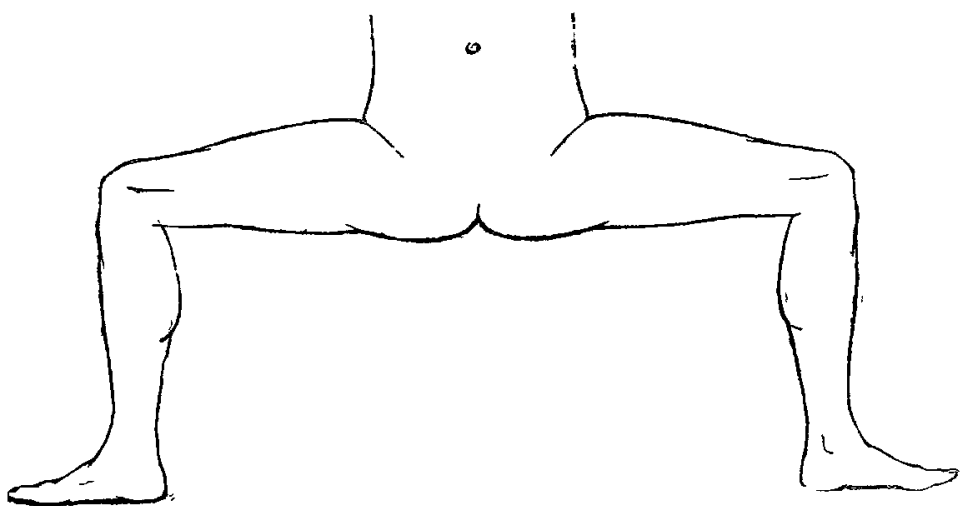

Right-angled position of thighs after operation.

5. Question: How long must this position be maintained before it is safe to alter it ?-Answer : Six months.

6. Question: What must be done subsequently ?-Answer : The limb must be gradually brought down to an increased angle with the body (Fig. 3). This process takes about a

FIG. 3.

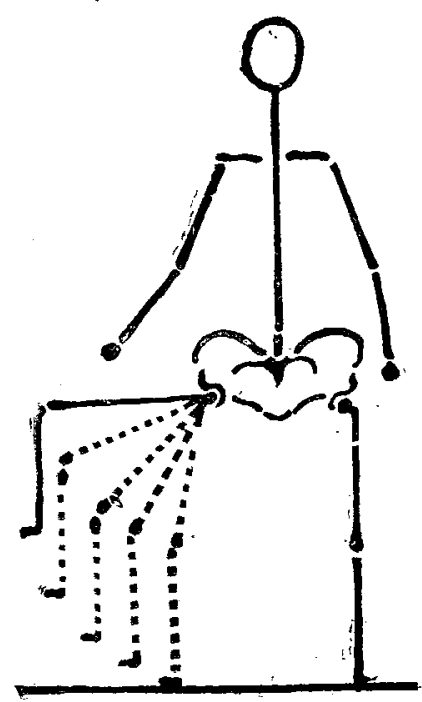

Showing gradual straightening of the limb.

year and the child is able to get about during that period. At the end of two years in the majority of cases the joint will be found strong and completely serviceable.

7. Question: Can we rely upon the result being always absolutely perfect?-Answer : The result depends to some extent upon the condition of the joints. We obviously expect the best results in those cases in which the bones are least defective in shape.

8. Question: What may we expect in the least farourable 
cases when the acetabulum is so rudimentary that it gives in itself no retaining support to the head of the femur?Answer: The result will probably be fairly good because the head of the femur will have made an artificial socket for itself by long-continued pressure in one position, and its retention in the socket will be assisted by the shortening of the muscles about the joint.

9. Question: What evidence have we to support this statement?-Answer: (1) We have the evidence of some continental surgeons who have seen such cases throughout the treatment. (2) We have the evidence of dissection of cases in which the patients have subsequently died from some independent affection. ${ }^{2}$ (3) We have the evidence of a good result following retention of the head of the femur at the normal level for two years ${ }^{3}$ although the reduction has not probably been complete. In the case referred to in the British Medical Journal three years after getting about there was less than half an inch shortening, although previously there had been two inches. If we get so good a result when the head of the femur has been only brought to the level of the acetabulum we may expect an equally good or better result when the joint surfaces have been kept in exact contact. (4) We have the evidence of pathological specimens showing that a very good acetabulum may be formed when a hip joint has been dislocated traumatically and has remained unreduced for a long time. As an example of such a newly formed joint I give Fig. 4.

FIG. 4.

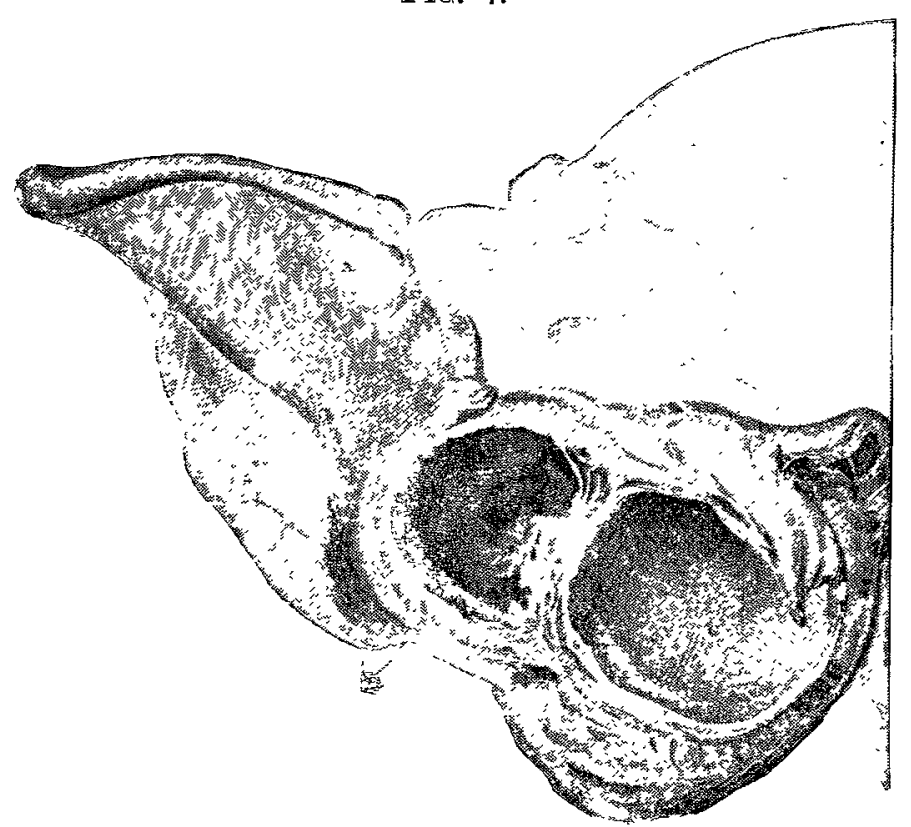

Reduced copy of a figure (Plate III.) in Sir Astley Cooper's "Dislocations and Fractures of the Joints," published in 1826. It represents " a dislocation into the foramen ovale which had never been reduced"; the new socket (c) had been formed, allowing " a considerable "degree of motion." This new socket held the head of the femur firmly. "I was lined by a ligamentous substance." Museum, St. Thomas's Hospital.

10. Question: What can we promise in any case as to the results? - Answer : We can promise that in any circumstances the patient will be benefited ; that is, will be better off than if no treatment had been carried out; that many will be absolutely cured and others greatly relieved.

11. Question: Is the so-called "bloodless" method of rupturing the contracted adductors, as advocated by Lorenz, satisfactory?-Answer: In children up to the ages of four, five, or perhaps six years a very moderate amount of firm pressure and massage of the adductors, held tense, will rupture their fibres, and although a certain amount of extravasation of blood will take place beneath the skin and around the site of the rupture the effect is satisfactory; and as some parents attach great importance to the avoidance of the use of the knife this procedure admirably serves our purpose. In older patients, or in any patient whose muscles are very firm, the section of the contracted parts with the knife is better.

12. Question: What are the comparative effects of the two methods of operation on the adductors, rupturing and

\section{Therapeutic Gazette Feb, 15th 1903}

3 Brit. Med. Jour., Nov. 6th, 1897. cutting the fibres?-Answer: 'The rupture of the adductors, which is effected by chopping and pressing with a sawing motion with the side of the hand (Lorenz's method), is effectual in overcoming the contraction, but besides causing extravasation of blood it often leads to abrasion of the skin. To be strictly accurate, it is, of course, not really "bloodless" when the surface of the skin bleeds ; and in the case of older patients, where the adductors are very firm, the abrasion may be severe. Division of the right muscles through an open wound is a very safe and satisfactory procedure, but it is necessary to protect the wound with a sterilised dressing during the subsequent manipulations required in the reduction of the displacement. I have found a combination of the two methods of operation satisfactory and effective. When the adductors are put upon the stretch in the position of rightangled abduction they are drawn away from the deep tissues and stand out as a well-defined body of muscle. Subcutaneous section of this prominent mass of muscle can be accomplished easily and safely, and if any deep fibres remain they can be broken down by abducting the thigh further. Thus we get rid of the contraction with very little extravasation of blood, with a clean-cut muscle, and with only a minute wound.

13. Question: What method should be adopted to retain the bones in their new and correct position?-Answer: A plaster-of-Paris casing has chiefly been used for this purpose and if thoroughly well applied, as done by Dr. Müller for Dr. Lorenz, it serves its purpose very well. However, it possesses some disadvantages. It involves keeping the patient under the anæsthetic for nearly an hour after the replacement has been effected, and if it should happen from any cause that a readjustment is necessary the removal of the plaster and its re-application are unavoidable. This is a tedious operation sometimes involving a second recourse to an anrsthetic. I have devised several forms of apparatus to take the place of the plaster-of-Paris and my most recent splint seems likely to prove satisfactory. It consists of a single iron splint A B (Fig. 5), to which is riveted a trough of iron, $\mathbf{C}$. This iron is rigid enough to maintain its form

FrG. 5.

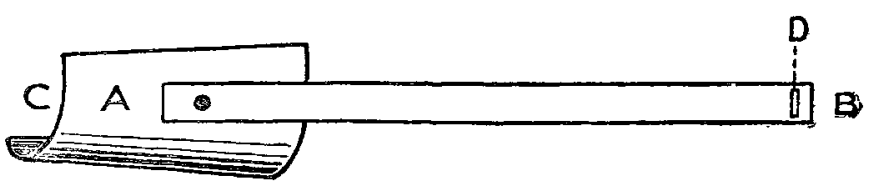

Splint for single displacement.

but soft enough to be bent as required by the surgeon: The trough is bent to fit half the circumlerence of the thigh, and the opposite side of the splint $(B)$ is bent round the crest of the ilium (Fig. 6). Of course, the splint is

FIG. 6.

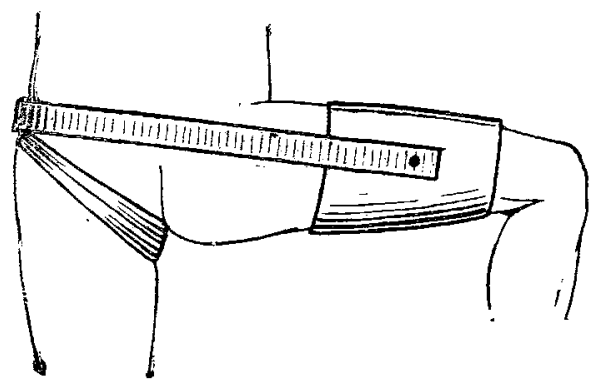

Splint for single displacement ; back view.

very thickly padded before it is applied. The thigh is then bandaged to the trough and the end (B), which encircles the opposite side in the region of the crest of the ilium, is also attached by flannel bandages. An opening in the iron band (D) enables the surgeon to fix his bandage firmly at this end. A perineal band on the sound side and a few turns of bandage round the waist suffice to keep the splint in position. This describes the splint for a single displacement. If the case is double a second splint is necessary for the other side (Fig. 7). In putting on the second splint it will require bending a little where it passes over the first at $E$. If a slot is made in each splint where they cross one another the two can be fixed together with a nut and screw. These splints are not only advantageous for the reasons 
already given, but they cost less than plaster-of-Paris bandages. Whether plaster-of-Paris or iron splints be used it is a very good plan to put a pair of soft drawers on the child first; these can be cut down the middle between the legs. When the bandages are used (about 20 are necessary) a very thick layer of wool should be applied over the drawers, kept in place by a plain bandage before the plaster ones are

FIG. 7.

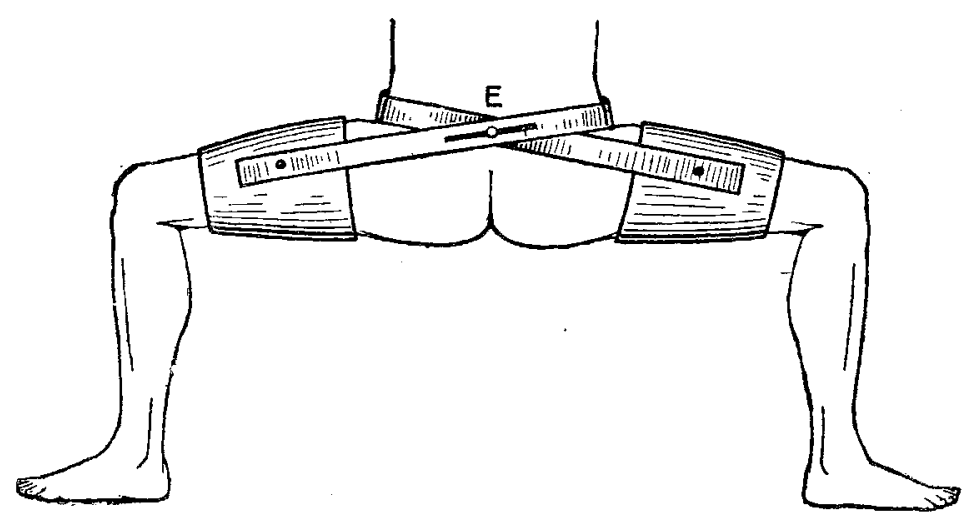

Splints for double displacement.

put on. If the iron splints are used the padding on the splints takes the place of the layer of wool referred to. The iron should be painted with velvril paint, which dries so rapidly that it can be used shortly before the splints are required. This paint is said to prevent rusting.

14. Question: Does the patient suffer much from this treatment?-Answer: Not more than from many operations. There has been a good deal of restlessness during the first night in nearly all the cases $I$ have seen operated on or have operated on myself. The temperature has risen to about $100^{\circ} \mathrm{F}$. and gradually subsided, reaching normal after four or five days or a week. The children have been quite comfortable and happy at the end of about three days. The peculiar position of the legs seems to give no trouble after the first or the second day. After about three weeks in bed the patients can get about on a stool with castors and, for a change in resting, I have devised a prone couch with a seat in the middle. If one leg only has been affected they manage to walk about with the help of a crutch extension from the thigh.

Queen Anne-street, W.

\section{ON A CASE OF TOXAEMIA OF OBSCURE ORIGIN.}

By LeONARD Williams, M.D. Glasg., M.R.C.P. LoNd., assistaNT PHYSICIAN TO THE GERMAN HOSPITAI, DALSTON.

THE lack of definite knowledge on the subject of toxic blood states and the obscurity of the origin of most of them are my excuse for recording a case presenting some very unusual features. Failures are proverbially more instructive than successes and the failure to make a correct diagnosis in this case may not be without its lessons for those who, like myself, regard the domain of pyæmia or septicæmia as a territory singularly in need of study and exploration.

On July 10th, 1902, a young woman, aged 22 years, came to consult me on account of some dyspeptic symptoms attended by a slight facial eruption. She had just come from the tropics, where a considerable portion of her life had been spent. The dyspepsia, which was accompanied by some anæmia, rapidly yielded to treatment and she went away from town for the summer. In the second week in September she returned to town to make preparations for a social function which was to take place on Oct. 1st. On Sept. 21st I saw her mother who told me that the patient had had an attack on the previous day which had alarmed them very much and which trom the description I took to be a rigor. I accordingly arranged to call at their house on the following day and to examine the patient in bed. The examination revealed the existence of a very marked lateral curvature with convexity towards the right which had been treated for some years with a measure of success. There was no pain or tenderness along the spine and the curvature seemed to offer no explanation of the supposed rigor. There was no tuberculosis in the family. The lungs were sound, the area of the heart was normal, and there were no bruits. The urine was free from albumin and sugar. The only other fact of importance which very careful examination of the patient could elicit was the existence of what appeared to be an ill-defined and somewhat tender mass in the region of the gall-bladder. The abdominal walls were thick and the nature of this mass was not at all easy to conjecture. It moved with respiration and with firm pressure seemed to disappear under the ribs backwards. The possibilities which presented themselves were enlarged gall-bladder and enlarged and unduly moveable kidney, though I am bound to say that neither of these appeared probable, nor did the possible existence of either serve to throw any light whatever on the supposed rigor. I left, requesting that if another attack should occur I might be apprised by telephone.

Two days later-i.e., on Sept. 24th-I had an opportunity of witnessing an attack which, I was informed, was exactly similar to the first. The patient was shivering so violently that the bedstead shook and her teeth chattered so incessantly that it was almost impossible for her to reply to my questions. There was, however, no complaint of pain and the mind was clear and even active. The pulse, full and bounding, numbered 110 ; the temperature, taken twice, was $102^{\circ} \mathrm{F}$, and the skin was dry and burning. On placing $m y$ hand over the suspected region and making pressure backwards to ascertain if there was anything more definite than on the occasion of my first examination, to my great astonishment the shivering suddenly ceased. Half an hour later the temperature was still $102^{\circ}$ but the pulse had fallen to 95 . Three hours later the pulse and temperature were normal, the patient expressed herself as quite well, and wanted to get up.

The sudden cessation of the rigor on abdominal pressure, together with the emotional factor supplied by the approach. ing social function gave rise to a suspicion in my mind that there might be a functional element in these ebullitions, and although I found it very difficult to reconcile this suspicion with the general bearing and attitude of the patient I decided to include some potassium bromide in the mixture of quinine and arsenic which $I$ prescribed.

From this day (Sept. 24th) to Oct. 9th-a period which included the social function with its attendant excitement and fatigue-the patient remained in excellent health and spirits. On the 10th, however, there was an unmistakeable rigor: another occurred on the 11th and yet another on the 12th. All these I saw and seemingly stopped by making pressure in the right hypochondrium. In all three the temperature was raised to over $101^{\circ}$, the skin was dry, and the pulse was rapid, much as on the first occasion. There were no sweats. The question of malaria had been carefully considered after the first attack and there seemed to be no reason whatever: for supposing that such a cause was at work. The increasing number of the attacks, which certainly did not lessen in severity, and the obscurity of the whole condition, made me anxious to clear up the question of the possible existence of a functional element. There was more than a little to be urged in favour of such a view and yet the whole aspect of the case seemed totally opposed to it. I therefore asked Dr. J. S. Risien Russell to see the patient with me. He examined very carefully not only her nervous but also her other systems and although he was unable to suggest a diagnosis he was quite positive that such evidences of a functional element as may have existed were the results of the obviously grave pathological state.

On the following day (Oct. 13th) Mr. W. Arbuthnot Lane saw the patient with me. He confirmed my observation of the existence of a somewhat tender mass in the right hypochondrium the nature of which was not clear. On accoun of the thickness of the abdominal walls and the difficulty of getting them relaxed, it was arranged that the patient should be anæsthetised on the following day with a view of defining, if possible, the nature of this mass. When we met to make this examination on the morning of the 14th we found that the patient had just had a rigor. Her temperature was $105^{\circ}$, the pulse was rapid, and for the first time since the attacks began the tongue was foul. As she was obviously too ill to narcotise then, it was arranged that as soon as it was practicable she should be taken to a nursing home with a view 